\title{
Fundamento, evolución, nodos críticos y desafíos de la educación ecuatoriana actual
}

Foundation, evolution, critical nodes and challenges of the Ecuadorian current education

\author{
Volumen 19, Número 1 \\ Enero-Abril \\ pp. 1-31
}

Este número se publica el 1 de enero de 2019

DOI: 10.15517/aie.v19i1.35715

Floralba del Rocío Aguilar-Gordón

Revista indizada en REDALYC, SCIELO

Revista distribuida en las bases de datos:

LATINDEX, DOAJ, REDIB, IRESIE, CLASE, DIALNET, SHERPA/ROMEO, QUALIS-CAPES, MIAR

Revista registrada en los directorios:

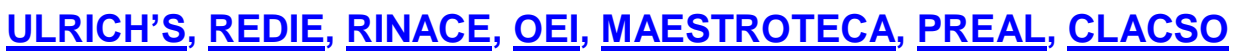




\title{
Fundamento, evolución, nodos críticos y desafíos de la educación ecuatoriana actual
}

Foundation, evolution, critical nodes and challenges of the Ecuadorian current education

\section{Floralba del Rocío Aguilar-Gordón ${ }^{1}$}

\begin{abstract}
Resumen: El ensayo presenta un análisis de los fundamentos de la educación en la historia de la humanidad, establece de manera breve, las características generales de la educación en el tiempo, determina el modelo (ideal educativo, rol de la persona docente, rol de la persona estudiante) imperante en cada etapa para comprender el dinamismo del ideal educativo y los rasgos característicos que configuran la educación ecuatoriana del presente. Asimismo, reflexiona acerca de las principales transformaciones, limitaciones o nodos críticos y desafíos de la educación ecuatoriana de los últimos tiempos. El ensayo argumenta la importancia de comprender que hablar de educación es volver la mirada a la persona como principal referente de intelección para entender las diversas manifestaciones socioculturales. Explica que toda orientación educativa tiene como fundamento las doctrinas filosóficas, por ello propone repensar el comportamiento de la educación a la luz de las leyes de la filosofía y del desarrollo cultural de la sociedad. En cuanto a la metodología, se trata de un estudio cualitativo, sustentado filosóficamente en el método fenomenológico-hermenéutico. Este ensayo abre caminos para posteriores investigaciones y para la generación de nuevas propuestas educativas en contexto.
\end{abstract}

Palabras clave: Ser humano, educación, educación superior, manifestaciones culturales.

Abstract: The essay presents an analysis of the foundation of the education in the history of the humanity, establishes in a brief way the general characteristics of the education in the time, there determines the model (ideal educational, role of the teacher, role of the student) commandingly in every stage to understand the dynamism of the ideal educational one and the typical features that form the Ecuadorian education of the present; he thinks brings over of the principal transformations, limitations or critical knots and challenges of the top Ecuadorian education of last times. This essay argues the importance of understanding that to speak about education is to turn the look to the human being as the principal modal of their own insight into to understand the diverse sociocultural manifestations. It makes clear that any educational orientation has as foundation to the philosophical doctrines for what it proposes to rethink the behavior of the education in the light of the laws of the philosophy and of the cultural development of the society. In the methodological field, it is a question of a qualitative study, sustained philosophically in the phenomenological-hermeneutic method. This test opens ways for later investigations and for the generation of new educational offers in context.

Keywords: Human being, education, higher education, cultural manifestations.

\footnotetext{
${ }^{1}$ Docente titular agregada con dedicación a tiempo completo y coordinadora del Grupo de Investigación en Filosofía de la Educación (GIFE) de la Universidad Politécnica Salesiana del Ecuador. Editora de la Revista Sophia. Colección de Filosofía de la Educación. Doctora en Filosofía. Magíster en Educación.
}

Dirección electrónica: faguilar@ups.edu.ec

Ensayo recibido: 27 de junio, 2018

Enviado a corrección: 26 de setiembre, 2018

Aprobado: 26 de noviembre, 2018 


\section{Introducción}

Hablar de educación es volver la mirada a su principio: al ser humano entendido como un sujeto bio-psico-social, un ser que piensa, que siente, que actúa y que construye su propia historia. Solamente las personas son capaces de conocer, de autocriticar, de cuestionar acerca del sentido, de la finalidad de sus saberes y de producir ciencia. La capacidad de asombro, la curiosidad innata de los seres racionales, la relación con la realidad inmediata es lo que impulsa a las personas hacia la generación del conocimiento. Todo retroceso y todo progreso sociohistórico-cultural depende del accionar consciente y libre de los seres humanos en donde la educación es la que humaniza a las personas las mismas que se autoproducen y como proyecto se van perfeccionando. En el pensamiento kantiano, "el hombre sólo por la educación puede llegar a ser hombre. No es nada más que lo que la educación hace de él" (Kant, 1803, p. 15). Conforme a Kant, "el hombre es la única criatura que ha de ser educada" (Kant, 1803, p. 3), puesto que gracias a su inteligencia puede conceptualizar, representar, crear, proponer, y transformar. Es la educación la que contribuye para el logro de grandes transformaciones de la humanidad y a su vez son las transformaciones educativas respaldadas en la filosofía las que fundamentan, dan sentido y significado a la existencia humana, no sin razón se considera que la educación ha sido históricamente el motor que impulsa todo proceso social.

De allí que, reflexionar acerca de los fundamentos de la educación en la historia y las transformaciones en la educación ecuatoriana actual implica determinar su propia entelequia, comprender las limitaciones, logros y desafíos que trae consigo la problemática educativa, lo cual abre nuevas aristas para la búsqueda de estrategias y para la aplicación oportuna con miras a solucionar los diversos problemas que experimenta el proceso educativo. Conviene abordar el tema de las transformaciones de la educación superior ecuatoriana actual, pues a ella le corresponde emprender varias tareas: determinar los vínculos necesarios con los niveles educativos precedentes; determinar su propia esencia; especificar el telos de la educación; comprender y ejercitar la integración de los saberes (ser, hacer, conocer y convivir); fortalecer el capital humano o desarrollo de la matriz cognitiva; generar una nueva epistemología que posibilite la formación de buenos profesionales que respondan a los requerimientos de la sociedad actual. En tal sentido, la reflexión sobre la educación en general y de la educación superior ecuatoriana actual, siempre será un tema vigente y de vital importancia; no obstante, a pesar de ello, en el país, se encuentran escasos estudios 
sobre su realidad, se organizan cursos, seminarios, foros y encuentros, pero todo queda reducido a la teorización aislada sin mayores esfuerzos de sistematización.

Los objetivos que direccionan este documento son: analizar los fundamentos de la educación para comprender el dinamismo del ideal educativo, los rasgos característicos que configuran la educación del presente, y sobre todo, reflexionar sobre los avances, limitaciones y desafíos de la educación ecuatoriana de los últimos tiempos. A continuación, se presenta una visión panorámica de los fundamentos de la educación en cada una de las etapas de la historia de la humanidad según el proceso histórico.

\section{Fundamento de la educación en la historia}

Pensar en el fundamento de la educación implica volver la mirada a su principal protagonista: la persona entendida como aquella que aprende deconstruye, construye y reconstruye, como aquella que es educable, es social y política por naturaleza. E fundamento de la educación invita a repensar en las personas que construyen nuevos referentes culturales, sociales y morales; conduce a realizar una visión retrospectiva y actual de la esencia y del fin mismo de la educación. Es imprescindible reflexionar sobre los fundamentos de la educación porque es ella una realidad que pertenece al devenir espaciotemporal de todas las personas; es acción-creación, construcción y transformación de la vida en sociedad. La educación es un quehacer activo y de orden psico-físico-social que permite la comprensión de nuevas realidades de acuerdo con el nivel de maduración interior de los sujetos. Por ello mismo, toda educación lleva consigo una cierta forma de desarrollo perfectivo de los seres humanos. De allí que, a decir de Knobel (1964):

[...] Es necesario superar el dualismo natura-nurtura, ya que hoy es aceptado prácticamente por todos, que el individuo es una consecuencia de la interacción, y que la personalidad es la resultante de la integración del individuo con sus caracteres genéticos-biológicos y el medio ambiente (p. 4).

Lo anterior, permite comprender que para que las personas se desenvuelvan en su entorno requieren del aprendizaje como un aspecto importante en su proceso de desarrollo. El proceso de aprendizaje y de educación lleva consigo una forma de desarrollo perfectivo. En tal sentido, en palabras de Knobel (1964), las distintas teorías del aprendizaje tanto las de carácter conductista sustentadas en el estímulo-respuesta, en el condicionamiento y en la 
imitación como base para sus explicaciones como las de carácter dinámico que valoran las diferentes interacciones (individuo-mundo; percepción inconsciente y reconocimiento de pautas heredadas e integradas con la realidad) como medio para comprender que el proceso de desarrollo está conformado por aspectos de crecimiento, de maduración y de aprendizaje.

Lo expresado prueba que los procesos de aprendizaje y de educación constituyen parte fundamental del desarrollo perfectivo, consciente y libre de las personas, pues la adhesión consciente de la voluntad a los principios y valores representa la forma característica del desarrollo perfectivo del proceso educativo. Por eso mismo, no podrá hablarse de educación cuando no exista conocimiento o autodeterminación en los sujetos, de allí que: "la educación se configura como el medio a través del cual adquirimos nuestro status humano" (Aguilar-Gordón, 2017c, p. 76).

En las siguientes tablas se esquematizan los hitos fundamentales de la educación en las antiguas civilizaciones del mundo oriental y en el mundo occidental, en ellas se presenta el ideal educativo y los roles tanto de docentes como de estudiantes. En la Tabla 1 se muestran los hitos fundamentales de la educación en las antiguas civilizaciones de la humanidad.

\section{Tabla 1}

Hitos de la educación en las antiguas civilizaciones

\begin{tabular}{|c|c|c|}
\hline $\begin{array}{lll}\text { Localidad } / / & & \\
\text { Objetivo } \quad 0 \quad \text { ideal }\end{array}$ & $\begin{array}{l}\text { Hitos fundamentales de } 1 \\
\text { civiliz }\end{array}$ & $\begin{array}{l}\text { educación en las antiguas } \\
\text { aciones }\end{array}$ \\
\hline educativo & ESTUDIANTES & DOCENTES \\
\hline $\begin{array}{l}\text { India: } \\
\text { Liberación de la } \\
\text { ignorancia (moksa). } \\
\text { Tres pilares } \\
\text { fundamentales: moral, } \\
\text { purificación de la mente y } \\
\text { sabiduría. }\end{array}$ & $\begin{array}{l}\text { Hombre: educado en } \\
\text { obediencia, respeto a los padres } \\
\text { y piedad hacia los dioses. } \\
\text { Mujer: aprende las virtudes de } \\
\text { someterse al marido, la } \\
\text { fidelidad, castidad, obediencia, } \\
\text { resignación, alegría y lleva con } \\
\text { perfección el hogar. }\end{array}$ & $\begin{array}{l}\text { El maestro (gurú) instruye, inicia y } \\
\text { guía al discípulo en su formación } \\
\text { espiritual. } \\
\text { Pueden acceder a la docencia los } \\
\text { miembros de las tres clases } \\
\text { superiores. }\end{array}$ \\
\hline $\begin{array}{l}\text { China: } \\
\text { Defensa de un orden } \\
\text { social y moral basado en } \\
\text { la autoridad y la }\end{array}$ & $\begin{array}{l}\text { Alcanza la perfección mediante } \\
\text { la introspección que le permita } \\
\text { conocer su mundo interior y el } \\
\text { estudio del mundo exterior. }\end{array}$ & $\begin{array}{l}\text { Es un hombre superior (Junzi) } \\
\text { cuya inteligencia, honestidad y } \\
\text { virtud lo diferencian de la mayoría. } \\
\text { Vive de manera sencilla, admira la }\end{array}$ \\
\hline
\end{tabular}




\begin{tabular}{|c|c|c|}
\hline $\begin{array}{l}\text { jerarquía. } \\
\text { Formación moral, } \\
\text { intelectual y guerrera. }\end{array}$ & $\begin{array}{l}\text { Alcanza el Li (conjunto de } \\
\text { normas interiores que } \\
\text { disciplinan las pasiones y crean } \\
\text { orden interno en la persona). } \\
\text { Valora la vida comunitaria. }\end{array}$ & $\begin{array}{l}\text { inteligencia, es comprensivo; } \\
\text { enseña el camino a la perfección: } \\
\text { el esfuerzo personal y la auto } \\
\text { perfección. Es guía y conocedor } \\
\text { de las capacidades de sus } \\
\text { estudiantes. }\end{array}$ \\
\hline $\begin{array}{l}\text { Egipto: } \\
\text { Dos modelos: casa de } \\
\text { instrucción y la escuela } \\
\text { de los escribas. } \\
\text { Disciplina y obediencia. }\end{array}$ & $\begin{array}{l}\text { Disponen de un silabario donde } \\
\text { aparecen ordenados los signos } \\
\text { usuales con su pronunciación y } \\
\text { significado. } \\
\text { Aprende de memoria y copian. }\end{array}$ & $\begin{array}{l}\text { Pertenecen a la casta de los } \\
\text { sacerdotes y su misión es } \\
\text { mantener su autoridad de casta } \\
\text { superior y la sumisión de las } \\
\text { castas inferiores. } \\
\text { La madre inculca las lecciones de } \\
\text { religión y de moral, emplea un } \\
\text { modo de enseñar rutinario. Los } \\
\text { docentes revisan los ejercicios } \\
\text { rectifican errores en el dibujo y en } \\
\text { la ortografía. }\end{array}$ \\
\hline $\begin{array}{l}\text { Mundo hebreo (Israel) } \\
\text { Ideal teocrático: formar al } \\
\text { hombre virtuoso, piadoso } \\
\text { y honesto. } \\
\text { La educación familiar fue } \\
\text { fundamental. }\end{array}$ & $\begin{array}{l}\text { Viven la voluntad de Dios y } \\
\text { cumplen la ley. } \\
\text { A la mujer le enseñan: las } \\
\text { Sagradas Escrituras, hilar, tejer, } \\
\text { cocinar, cuidar rebaño y la } \\
\text { administración de los bienes. } \\
\text { A los niños y jóvenes les } \\
\text { enseñan: ley de Dios, historia } \\
\text { sagrada, mandamientos y } \\
\text { preceptos. }\end{array}$ & $\begin{array}{l}\text { Método de enseñanza: repetición } \\
\text { (memoria) y revisión (forma } \\
\text { dialogada). } \\
\text { Inicia al interior de la familia y los } \\
\text { padres son los encargados de } \\
\text { traspasar sus tradiciones a los } \\
\text { hijos, de asegurar la presencia y } \\
\text { adoración de Dios, de transmitir la } \\
\text { herencia histórica, de enseñar la } \\
\text { conducta ética y moral (principios } \\
\text { básicos de disciplina y conducta). }\end{array}$ \\
\hline
\end{tabular}

Fuente: Construcción propia a partir de Marrow, 2014; Redondo et al, 2014.

Los principios enunciados en la educación en las antiguas civilizaciones no resultaron ajenos al contexto educativo ecuatoriano, en el cual, luego de la conquista, se instauró un sistema educativo restringido, sexista y clasista en el que la educación estaba direccionada exclusivamente para los hombres. La educación para las mujeres se dirigía al aprendizaje de las tareas propias del hogar: barrer, hilar, tejer, coser, cocinar, lavar, y sobre todo era 
fundamental el aprendizaje de virtudes, de fidelidad, de obediencia y de sometimiento a las disposiciones del esposo, direccionadas al cumplimiento de la voluntad de Dios. Se prioriza el método de la reiteración (memoria) que inicia al interior de la familia. En el proceso histórico, se identifica que los fundamentos de la educación en la antigua Grecia se encuentran orientados al cumplimiento del ideal central: la formación intelectual y la educación física; por ello, sostenían que: "Una educación buena es la que puede dar al cuerpo y al alma toda belleza y toda la perfección de que son susceptibles" (Redondo et al, 2014, p. 113). Sin embargo, este ideal educativo en la Grecia antigua configura diferentes matices de acuerdo con las condiciones sociales, históricas, políticas y económicas de cada una de las ciudades, tal como se puede apreciar en la Tabla 2.

Tabla 2

Hitos de la educación en la antigua Grecia

\begin{tabular}{|c|c|c|}
\hline Localidad // & Hitos fundamentales de la e & lucación en las antigua Grecia \\
\hline $\begin{array}{l}\text { Objetivo o ideal } \\
\text { educativo }\end{array}$ & ESTUDIANTE & DOCENTE \\
\hline $\begin{array}{l}\text { Paideia Arcaica } \\
\text { (areté física que cultiva el } \\
\text { cuerpo y areté espiritual, } \\
\text { que incluye la formación } \\
\text { cultural y moral). Base de } \\
\text { la educación griega. }\end{array}$ & $\begin{array}{l}\text { Solo al alcance de los mejores. } \\
\text { Mujeres y esclavos no son } \\
\text { considerados ciudadanos con } \\
\text { derechos políticos. } \\
\text { El Estado no tiene la obligación } \\
\text { de garantizar su educación. }\end{array}$ & $\begin{array}{l}\text { Utiliza la mnemotécnica, la } \\
\text { violencia y los castigos corporales } \\
\text { como forma de desarrollar la } \\
\text { disciplina en los estudiantes. Los } \\
\text { esclavos sirven como maestros } \\
\text { "pedagogos domésticos". La } \\
\text { posición social del maestro no es } \\
\text { de prestigio. El oficio de enseñar } \\
\text { es para quienes caen en } \\
\text { desgracia. }\end{array}$ \\
\hline $\begin{array}{l}\text { Paideia Espartana } \\
\text { (forma a los ciudadanos } \\
\text { en las destrezas de la } \\
\text { guerra y en la } \\
\text { participación en la vida } \\
\text { civil y política de la } \\
\text { ciudad) }\end{array}$ & $\begin{array}{l}\text { El ideal de ser humano para que } \\
\text { sea formado tiene como base la } \\
\text { obediencia, la disciplina, la } \\
\text { templanza, la sobriedad, la } \\
\text { austeridad en la vida cotidiana y } \\
\text { la resistencia al dolor y al } \\
\text { sufrimiento }\end{array}$ & $\begin{array}{l}\text { Estructura social y educativa } \\
\text { basada en el adiestramiento en el } \\
\text { manejo de las armas, en las } \\
\text { virtudes de obediencia y disciplina } \\
\text { propias del guerrero. La escuela } \\
\text { se organiza como un cuartel } \\
\text { militar. }\end{array}$ \\
\hline $\begin{array}{l}\text { Paideia Ateniense } \\
\text { (areté física y espiritual) }\end{array}$ & $\begin{array}{l}\text { Extranjeros, mujeres y esclavos } \\
\text { quedan excluidos } \\
\text { La formación del ciudadano es }\end{array}$ & $\begin{array}{l}\text { Tiene la función de formar la } \\
\text { mente y el cuerpo. } \\
\text { Su tarea es garantizar el orden }\end{array}$ \\
\hline
\end{tabular}




\begin{tabular}{|c|c|c|}
\hline $\begin{array}{l}\begin{array}{l}\text { Concepto de dike } \\
\text { (justicia) }\end{array} \\
\text { Equilibrio } \\
\text { comunidad e individuo. } \\
\text { Educación cívica. }\end{array}$ & $\begin{array}{l}\text { física, moral, espiritual, formado } \\
\text { con mentalidad de servicio a la } \\
\text { polis. } \\
\text { Sócrates propuso la mayéutica, } \\
\text { con sus estudiantes para que } \\
\text { aprendieran por medio de } \\
\text { métodos activos que } \\
\text { promovieran la participación, el } \\
\text { diálogo y la reflexión. }\end{array}$ & $\begin{array}{l}\text { cósmico, soporte del mundo, de la } \\
\text { sociedad y del individuo. }\end{array}$ \\
\hline $\begin{array}{l}\text { Paideia Helenística } \\
\text { (Formación competa e } \\
\text { integral física, intelectual } \\
\text { y cultural) }\end{array}$ & $\begin{array}{l}\text { Aprende a leer mediante un } \\
\text { método alfabético } \\
\text { Recibe una formación poética y } \\
\text { musical } \\
\text { Redacta sus propias } \\
\text { composiciones en las que } \\
\text { imitará los modelos en } \\
\text { oraciones, discursos fúnebres, } \\
\text { etc. }\end{array}$ & $\begin{array}{l}\text { La madre, pedagoga o nodriza } \\
\text { enseñan las costumbres y virtudes } \\
\text { morales. } \\
\text { El padre se ocupa de las primeras } \\
\text { enseñanzas encaminadas a } \\
\text { mantener las tradiciones. }\end{array}$ \\
\hline
\end{tabular}

Fuente: Construcción propia a partir de Redondo et al., 2014.

Estableciendo un paralelo con los procesos experimentados en la educación ecuatoriana, históricamente encontramos que el ideal ha sido la formación moral del ser humano, el desarrollo de principios y valores éticos que redunden en la vida social. Por otra parte, el sistema educativo ecuatoriano siempre se ha preocupado por la formación física del ser humano, aspecto que desde la colonia se ha visto reflejado en las diferentes redes curriculares bajo la denominación de educación física, cultura física, etc. La profesión docente en el Ecuador ha sido vista como una actividad social de menor jerarquía frente a las otras profesiones, ha sido una profesión mal remunerada y de excesiva explotación por parte de quienes tienen el poder.

En la Tabla 3 se presentan los principales referentes educativos evidenciados en la Edad Media, en el Humanismo y en el Renacimiento. 
Tabla 3

Hitos de la educación en la edad media y en el renacimiento

\begin{tabular}{|c|c|}
\hline \multirow[t]{2}{*}{ Representante } & \multirow[t]{2}{*}{ Hitos fundamentales de la educación en la Edad Media y en el Renacimiento } \\
\hline & \\
\hline San Agustín & $\begin{array}{l}\text { Educación con amor y evita el castigo. } \\
\text { Cada uno llevamos el conocimiento dentro de nosotros. } \\
\text { El conocimiento de cada cosa se basa en Dios. } \\
\text { "Lo decisivo es la formación de la voluntad; ...Educar significa sacar el corazón de la persona } \\
\text { estudiante de una situación de presente para llevarlo más allá, hacia su futuro como persona y como } \\
\text { miembro de una comunidad; ...Los alumnos enseñan a través de sus maestros lo que aprenden de } \\
\text { ellos, y los maestros aprenden en aquellos lo mismo que les enseñan...El oficio de maestro será } \\
\text { trasmitir ciencia y sabiduría para llevar a la Sabiduría" (San Agustín, 2018, p. 1) }\end{array}$ \\
\hline Humanismo & $\begin{array}{l}\text { Luis Vives considera que cada estudiante tiene constituciones físicas diferentes, las cuales deben ser } \\
\text { atendidas durante su educación. } \\
\text { Además de los rasgos corporales, el estudiantado presenta diferencias en sus capacidades } \\
\text { intelectivas. La educación debe ajustarse a sus particulares capacidades de inteligencia, memoria e } \\
\text { imaginación. } \\
\text { Luis Vives sostiene que tiempo y paciencia son necesarios para conseguir una educación óptima en } \\
\text { personas con capacidades diversas. }\end{array}$ \\
\hline Renacimiento & 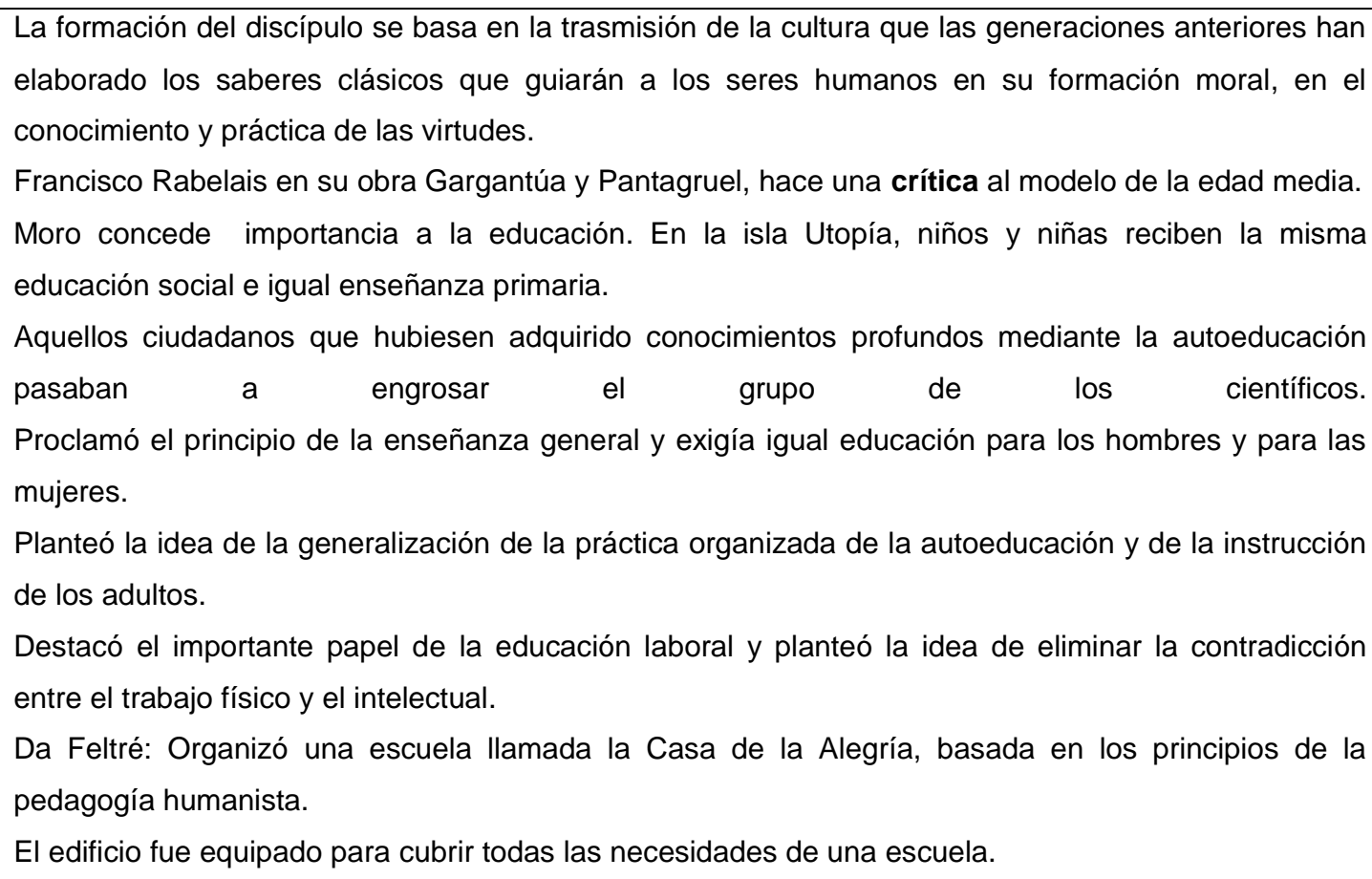 \\
\hline
\end{tabular}

Fuente: Construcción propia a partir de García, 2017; Redondo et al., 2014; Uzcátegui y Junguittu, 2017. 
Al relacionar los principios de la educación medieval, humanista y renacentista de la tabla precedente con el sistema educativo ecuatoriano, se puede manifestar que, de manera asincrónica, las ideas pedagógicas de los grandes teóricos de aquellas épocas contribuyeron notablemente para la estructuración de diferentes modelos pedagógicos que se pusieron en ejecución en nuestro contexto. En la actualidad se habla de una educación con amor y con el corazón, una educación que evite el castigo (esto último es duramente sancionado por la normativa ecuatoriana). En los últimos tiempos, la educación ecuatoriana considera y valora las diferencias individuales tanto en sus rasgos corporales como las diferencias en las capacidades intelectivas, aspecto que se encuentra reglamentado bajo la llamada educación inclusiva. Actualmente, la educación ecuatoriana promueve la necesidad de tener presente las capacidades diferentes en inteligencia, memoria e imaginación de las personas. Ahora, la educación ecuatoriana en sus leyes establece una educación para todas las personas en igualdad de condiciones.

En este breve intento de localización de los principales hitos de la educación en la historia. A continuación, en la Tabla 4 se proponen los principales referentes educativos de la Época Moderna.

Tabla 4

Hitos de la educación en la verdad Moderna

\begin{tabular}{|l|l|}
\hline Representante & Hitos fundamentales de la educación en la Edad Moderna \\
\hline Montaigne & $\begin{array}{l}\text { Las instituciones educativas y las comunidades científicas valoran cada vez } \\
\text { más la simulación del saber que el saber mismo. } \\
\text { En las escuelas se enseñan muchas cosas pero no se aprende a pensar ni a } \\
\text { hacer: los estudiantes acumulan en su memoria más información, pero son } \\
\text { incapaces de usar sus conocimientos en forma independiente, no relacionan lo } \\
\text { que saben con sus vidas. } \\
\text { Los maestros se concentran en contenidos y no aprovechan la riqueza de la } \\
\text { vida, de la naturaleza y de la sociedad que son un texto más rico y más seguro. } \\
\text { La educación debe ser activa basada en el desarrollo de capacidades naturales } \\
\text { y habilidades del estudiantado. } \\
\text { No sirve de nada llenar la cabeza de información y conocimiento si no pueden } \\
\text { pensar con independencia y obrar bien. } \\
\text { El maestro debe hablar poco y escuchar más. }\end{array}$ \\
\hline
\end{tabular}




\begin{tabular}{|l|l|}
\hline Comenio & Es necesario combinar teoría y práctica. \\
& $\begin{array}{l}\text { Estructuró la ciencia autónoma y estableció sus principios fundamentales } \\
\text { Diseño la obra Didáctica Magna } \\
\text { Pampedia como la educación universal de todo el género humano (Bedoya, } \\
\text { 2003, p. 110); intenta comprender la educación desde la concepción integral } \\
\text { del hombre. } \\
\text { Creador de la Escuela Maternal, Elemental, Latina o Gimnasio y la Academia }\end{array}$ \\
\hline Descartes & $\begin{array}{l}\text { Fundamenta el pensamiento racional. } \\
\text { Vivir sin filosofar propiamente es tener los ojos cerrados sin querer abrirlos } \\
\text { jamás } \\
\text { Las naciones son tanto más civilizadas cuando mejor filosofan sus hombres. } \\
\text { Pienso, luego existo. } \\
\text { Disciplinario Educativo }\end{array}$ \\
\hline Locke & $\begin{array}{l}\text { La mente de un niño es como una tabla rasa, es la experiencia la encargada de } \\
\text { darle forma. } \\
\text { Es mejor aprender de forma experimental en lugar de los libros } \\
\text { Las experiencias empíricas son consideradas como medio de aprendizaje } \\
\text { Aprendizaje con juegos }\end{array}$ \\
\hline Rousseau & $\begin{array}{l}\text { Todo cuanto sale de las manos de Dios es bueno y todo degenera en manos } \\
\text { de los hombres } \\
\text { El hombre es bueno por naturaleza } \\
\text { Propone un sistema educativo que permita al hombre natural vivir con esapta } \\
\text { Se educa al ciudadano ideal. }\end{array}$ \\
\hline
\end{tabular}

Fuente: Construcción propia a partir de Bedoya, 2003; García, 2017; Redondo et al., 2014; Uzcátegui y Junguittu, 2017.

De manera similar a los hitos fundamentales de la modernidad europeo-occidental, presentados en la Tabla 4, en la educación ecuatoriana de los últimos tiempos se observa que las instituciones educativas valoran más el saber hacer, más que el saber mismo. Esto, a diferencia de lo experimentado en siglos anteriores, en los que en las instituciones educativas se evidenciaba un marcado enciclopedismo y la tendencia a acumular memorísticamente contenidos y conocimientos poco críticos y nada reflexivos. Ahora se trata de que el aprendizaje sea significativo, sustentado en la experiencia, útil para la vida y contextualizado. Con la incorporación de nuevos modelos y estrategias educativas se 
procura que el profesorado hable menos y pueda escuchar más al estudiantado. En fin, en el sistema educativo se promueve la necesidad de articular teoría y praxis.

Para finalizar el recorrido histórico con la localización de los principales fundamentos de la educación, se presenta la Tabla 5, en la que se destacan los principales aportes a la educación realizados en la época contemporánea.

Tabla 5

Hitos de la educación en la época contemporánea

\begin{tabular}{|c|c|}
\hline Representante & Hitos fundamentales de la educación en la época contemporánea \\
\hline Pestalozzi & $\begin{array}{l}\text { Reforma la pedagogía tradicional } \\
\text { Promulga una educación popular, su objetivo es adaptar el método de } \\
\text { enseñanza de desenvolvimiento natural del niño considerado como armonioso. } \\
\text { El conocimiento humano comienza con la intuición sensible de las cosas y a } \\
\text { partir de ellas se forman las ideas. } \\
\text { A los niños no se les deben proporcionar conocimientos ya construidos, sino la } \\
\text { oportunidad de aprender sobre sí mismos mediante la actividad personal. } \\
\text { Los profesionales de la educación deben estar preparados para lograr un } \\
\text { desarrollo integral del alumnado más que para implantarles conocimientos esto } \\
\text { sólo constituye una parte de la educación. } \\
\text { El verdadero objetivo de la educación es formar un "hombre moral" total, un ser } \\
\text { que haga el bien, que sus acciones se basen en la fe y que deje a un lado su } \\
\text { egoísmo. } \\
\text { Su lema fue "El aprendizaje por la cabeza, la mano y el corazón". }\end{array}$ \\
\hline Montessori & $\begin{array}{l}\text { Crea el método Montessori caracterizado por desarrollar en el niño la } \\
\text { independencia, la libertad con límites, respetar la psicología natural y el } \\
\text { desarrollo físico y social del niño. } \\
\text { Este modelo educativo se caracteriza por poner énfasis en la actividad dirigida } \\
\text { por el joven ilustre y la observación clínica por parte del maestro. Esta } \\
\text { observación tiene la intención de adaptar el entorno de aprendizaje del joven a } \\
\text { su nivel de desarrollo. } \\
\text { El propósito de este método es liberar el potencial de cada joven para que se } \\
\text { autodesarrolle en un ambiente estructurado. El método nace de la idea de } \\
\text { ayudar al niño a obtener un desarrollo integral para lograr un máximo grado en } \\
\text { sus capacidades intelectuales, físicas y espirituales. Trabaja sobre bases } \\
\text { científicas en relación con el desarrollo físico y psíquico del niño. }\end{array}$ \\
\hline
\end{tabular}




\begin{tabular}{|l|l|}
\hline & $\begin{array}{l}\text { María Montessori basa su método en el trabajo del niño y en la colaboración } \\
\text { adulto - niño. } \\
\text { La escuela no es «un lugar donde el maestro transmite conocimientos», sino } \\
\text { «un lugar donde la inteligencia y la parte psíquica del niño se desarrollará a } \\
\text { través de un trabajo libre con material didáctico especializado». El niño, con su } \\
\text { enorme potencial físico e intelectual, es un milagro frente a nosotros. }\end{array}$ \\
\hline Freire & $\begin{array}{l}\text { El maestro es el ente que orienta a las personas a pensar la sociedad en la que } \\
\text { se desarrolla su proceso de aprendizaje, construye desde sus conocimientos } \\
\text { previos y desde su realidad social concreta. } \\
\text { La persona que aprende construye el conocimiento como un acto político, } \\
\text { desde la relación con el maestro y los demás aprendices dentro del aula, para } \\
\text { pasar de seres sociales pasivos a seres sociales activos, críticos y pensantes } \\
\text { dentro y fuera del aula. } \\
\text { Pedagogía crítica no educación bancaria. }\end{array}$ \\
\hline
\end{tabular}

Fuente: Construcción propia a partir de García, 2017; Redondo et al., 2014; Uzcátegui y Junguittu, 2017.

De los hitos analizados en la tabla anterior, en el contexto educativo ecuatoriano de los últimos tiempos, se evidencia la presencia de la inclusión de metodologías que promueven el desenvolvimiento natural del estudiantado, se propicia el aprendizaje autónomo mediante el uso de estrategias didácticas que otorgan la oportunidad de generar aprendizajes propios, se promueven aprendizajes integrales sustentados en los cuatro pilares fundamentales de la educación propuestos por la Organización de las Naciones Unidas para la Educación, la Ciencia y la Cultura (UNESCO , 2008). Se utilizan las didácticas metodológicas propias de la Pedagogía Crítica y de tendencia constructivista. Los escenarios de la educación son ricos y variados, en su mayoría superan el ambiente educativo restringido a cuatro paredes y se han priorizado la naturaleza, espacios sociales, espacios virtuales, etc.

En el proceso sufrido por la educación en el tiempo, se ha evidenciado que no puede existir una propuesta pedagógica sin un referente filosófico que lo respalde y sin un ideal que señale el camino que se debe seguir. El principal fundamento de todo proceso educativo, independientemente del contexto en el que surja, es, ha sido y será el ser humano quien genera los cambios necesarios para enfrentar cada época histórica y cada situación contextual que le corresponde vivir. Es así como, en el documento, se pretende realizar una 
visión panorámica de la educación ecuatoriana de los últimos tiempos para determinar sus aportes, limitaciones o nodos críticos y desafíos a enfrentar.

\section{Notas características sobre la evolución de la educación en el Ecuador}

La educación en el país nunca tuvo un proceso realmente ejecutable, es decir, existieron proyectos con buenas intenciones pero que no encontraron el espacio para hacerse realidad debido a circunstancias como falta de recursos económicos, falta de preparación del talento humano encargado de ejecutarlos, desajuste contextual, por cuanto muchas de las reformas que se han pretendido llevar a cabo han sido ajenas al contexto.

Las mismas políticas de Estado, en una buena parte del proceso histórico han priorizado otros sectores como el pago de la deuda externa (excepción de la última década), dejan a un segundo plano las políticas y prácticas educativas. Históricamente encontramos que, desde el gobierno de Juan José Flores en 1830 hasta el gobierno de Francisco Robles en 1859 (a excepción de Vicente Rocafuerte ${ }^{2}$ ), es notoria la tendencia a entender la educación como un privilegio de pocos y no como un derecho de todos.

En el gobierno de García Moreno se experimentaron los primeros cambios de trascendencia en la educación pública del país, se empieza a consolidar un plan paralelo (economía y educación) que permite la creación de diversas instituciones educativas como la Escuela Politécnica Nacional. Durante este gobierno, se importó un modelo educativo europeo que, para aplicarlo, obligó a incorporar en el país a los Padres Jesuitas, a los Hermanos Cristianos y a las religiosas de los Sagrados Corazones para que fueran todos ellos los responsables de la formación educativa de los niveles de educación primaria y de educación secundaria (como se denominaba en ese entonces) y a las Hermanas de la Caridad para que se encargaran de los hospitales. Para los estudios superiores trajo profesionales (doctores y sabios maestros) alemanes.

La nueva doctrina estaba impulsada con programas que potenciaban la sumisión y el cumplimiento de tareas, sin opción al desarrollo del pensamiento analítico, crítico, reflexivo que poco a poco cobraba fuerza en el ámbito internacional con el liberalismo; al contrario, en el país se fortalecía la tendencia teocrática que sostenía que Dios era el centro de aprendizaje y que todo era dado por él. En aquella época estuvo fuertemente acentuada la

\footnotetext{
2 Fundó escuelas, colegios, museos; creó la Dirección General de Estudios con la idea de responder a ciertas necesidades educativas, sin embargo, esto tuvo mayor incidencia en el país porque todo se centralizó en Quito y Guayaquil.
} 
creencia religiosa a tal punto que obligó a establecer como requisito (no excluyente) para poder estudiar: Ser católico.

Al revisar los procesos históricos, Moreira (2013) encuentra que en el período progresista no se mantuvieron los avances educativos logrados durante el garcianismo, sino que, al contrario, se retrocede y perjudica a los indígenas de la Sierra y a los campesinos de la Costa, esta situación trajo consigo dos fenómenos importantes que marcaron el atraso del país: aumento demográfico y analfabetismo creciente.

Según las investigaciones realizadas por Moreira (2013), a fines del siglo XIX, con la llegada del liberalismo en 1895 y con Eloy Alfaro, en 1897 se establece a la educación como una instrucción pública, gratuita, laica y obligatoria hasta la primaria. Este último principio no generó un impacto inmediato en el país, pues el control de la educación estaba dado por la religión y desde sus postulados. Los religiosos seguían manteniendo la enseñanza y dentro de lo laico estaba inmersa la religión católica y sus modelos de aprendizajes.

En la primera década del siguiente siglo, con la constitución de 1907, se establece la separación Iglesia-Estado. Se definen las funciones que le corresponden al Estado y las tareas que le conciernen a la Iglesia. Se empieza a generar, de manera desordenada, un nuevo proceso educativo que tenía como principio el conocimiento de forma utilitaria, nuevos problemas se empiezan a suscitar. El Gobierno de Alfaro para organizar un modelo efectivo, que no se vea amenazado por las prácticas religiosas, crea los normales en Quito, Guayaquil y Cuenca para formar maestros que impartan una educación laica.

De acuerdo con Moreira (2013), después del período liberal, los gobiernos subsiguientes se preocuparon de la organización y fortalecimiento estatal en materia legal y económica, y se despreocupan nuevamente del proceso educativo, un proceso que en más de 100 años no logra consolidarse, que sufre reformas y que es cambiado permanentemente como consecuencia de la imposición de "ideologías" doctrinales y personales que surgen con la finalidad de mantener el poder y las estructuras estatales.

Es así como la educación en el país no fue atendida hasta 1946, con la décimo sexta constitución, misma que estipulaba que la educación es un derecho de los hijos y un deber de los padres. En esta Constitución se empieza a fortalecer la educación particular con recursos municipales y con presencia en la Dirección Nacional de Enseñanza. En este momento, las universidades públicas y particulares del país se consideran autónomas. 
Un aspecto que ha dinamizado y obstaculizado el devenir educativo ecuatoriano ha sido el cambio continuo de presidentes sin terminar su mandato, eso hizo que en los 17 años siguientes no se pueda organizar o llevar a cabo un nuevo plan educativo que mejore el sistema nacional que, para esa época, se fortalecía en inequidad donde la calidad de enseñanza se demostraba solo en la capital y el nombramiento de los maestros se realizaba sin seguir un debido proceso que garantizara la selección y el reclutamiento de los docentes.

En algunos estudios realizados por diversos investigadores como Moreira (2013) se encuentra que en 1963, en tiempos de la Junta Militar se crea un Programa Nacional de Alfabetización y Educación para Adultos, el cual empieza a dar resultados positivos en el país aunque los resultados posteriores no fueron alentadores, ya que, al contrario, procedieron al cierre de universidades que no respondían a sus intereses y que levantaban sus voces de protesta, es el caso de la Universidad Central del Ecuador, institución que cerraron en tres ocasiones.

Después de la sucesión de varios presidentes (Golpe de Estado en contra de Velasco Ibarra), aparece, en Ecuador, un proceso de trasformaciones liderado por la dictadura militar (mejora la economía por el boom petrolero), es una época en la que se crearon varias escuelas en zonas rurales. Posteriormente, en el año 1988, surgió la educación bilingüe, pero nuevamente el crecimiento se da de forma infraestructural, no se generaban procesos de aprendizaje que contribuyeran con el desarrollo social. Después de los gobiernos dictatoriales y con el retorno a la democracia producida en 1979 mediante el triunfo del Partido Concentración de Fuerzas Populares que lleva al poder a Jaime Roldós Aguilera, se producen procesos importantes como el Plan Nacional de Alfabetización de Roldós y la Ley Orgánica de Educación; sin embargo, los siguientes gobiernos se preocuparon más por organizar la parte administrativa de la educación a través de la creación de la Ley de Carrera Docente y Escalafón del Magisterio Nacional.

Como consecuencia de la Conferencia Mundial sobre la educación, realizada en 1990 en Tailandia, se pone la mirada en la educación y se considera pertinente realizar reformas educativas que respondan a las nuevas exigencias locales y mundiales, es así como el país también entra en la misma dinámica, y en 1996, los esfuerzos por mejorar la educación se direccionan hacia la Reforma Curricular Consensuada para la educación básica ecuatoriana, una educación por objetivos, la cual es plasmada en el Plan Estratégico de Desarrollo de la Educación Ecuatoriana 1997-1998. 
Por su parte, el Informe "Evaluación común de país", presentado por las Naciones Unidas (década de los años 90 y presentado en el año 2002) hacía notar que la inversión en la última década del siglo XX fue inferior a la de las dos décadas anteriores y que la población rural tuvo la mitad de escolaridad formal que la urbana, además de una tasa elevada de analfabetismo. Mientras en Ecuador la inversión estatal en educación se reducía a inicios de los 90, existían pronunciamientos internacionales por generar la accesibilidad de los niños y niñas a los centros educativos, por ese motivo la UNESCO (2008) y su movimiento de Educación Para Todos (EPT) crearon un foro en Jomtien-Tailandia donde delegados de 155 países y 150 organizaciones gubernamentales y no gubernamentales acordaron cumplir un marco de acción para satisfacer las necesidades básicas de aprendizaje y para garantizar la universalidad del acceso a la educación. Es así como definieron métodos y estrategias para satisfacer estas necesidades en 10 años; no obstante, para el año 2000 no se cumplieron los objetivos definidos y Ecuador era uno de los países que ni siquiera había podido entrar en el proceso de educación preescolar.

A decir, de Ayala-Mora (2015), en los años noventa, en que se desató la crisis de la desregularización bancaria y la dolarización, se produjo la crisis de la Educación Superior. Las dificultades acumuladas en medio del divorcio de la universidad con el Estado trajeron consigo más problemas que obligaban a implementar reformas reales y efectivas. El sistema de total auto regularización llegó a situaciones límite como el manejo del Consejo Nacional de Universidades y Escuelas Politécnicas (CONUEP) de los años finales del siglo XX, en que se dio con mayor fuerza la creación desordenada de universidades y el deterioro del nivel académico. El establecimiento del CONESUP y la aplicación de la Ley del 2000 fueron soluciones parciales porque los principales organismos de control estuvieron manejados por gente corrupta y sin preparación. En términos de Ayala-Mora (2015): "En 1996 existían 10 instituciones superiores en el Ecuador. A inicios del siglo XXI el número había llegado a 72" (p. 13), lo cual evidencia la multiplicación de universidades privadas en Quito, Guayaquil y Cuenca como principales ciudades capitales de las provincias de Pichincha, de Guayas y de Azuay, respectivamente. Ya para el año 2000, las universidades en el país estaban distribuidas así: en Quito funcionaban 18, en Guayaquil operaban 9 y en Cuenca se encontraban 4, lo que significaba que el $40 \%$ de las universidades estaban concentradas en las tres ciudades principales del país. 
Es así como en la Constitución (1998) ${ }^{3}$, en medio de un gobierno cuestionado, se crea una nueva norma jurídica que establecía que la educación estaba garantizada por el Estado en igualdad de condiciones y oportunidades; era un derecho irrenunciable de las personas; sería ética, pluralista, democrática, humanista y científica; estaba garantizada para personas con discapacidad, otorga libertad de enseñanza y de cátedra, fortalece prioritariamente las zonas rurales y fronterizas. Normativa que direccionaría las políticas y las acciones gubernamentales e institucionales. La asignación mínima del treinta por ciento de los ingresos corrientes totales del gobierno central, para la educación y la erradicación del analfabetismo, permitirían el desarrollo del país.

Es menester, manifestar que, en la revisión retrospectiva de los procesos educativos experimentados en el país, en el 2006 se realiza una consulta popular en la que se aprobaron ocho políticas del nuevo Plan Decenal 2006-2015. Los objetivos del Plan Decenal eran desconocidos por la ciudadanía, sin embargo, a decir de Ayala-Mora (2015), el Plan Decenal se aprobó con el $67.08 \%$ y los expertos educativos esperaban que el compromiso de garantizar la calidad de la educación nacional con equidad, visión intercultural e inclusiva, desde un enfoque de los derechos y deberes para fortalecer la formación ciudadana y la unidad en la diversidad de la sociedad ecuatoriana se cumpliera.

Desde el año 2007 el escenario educativo toma un rumbo diferente, empieza a existir un gran aporte económico gracias a las bonanzas dadas por el aumento del precio del barril petrolero en el 2008, y se empieza a generar una estructura estatal sólida para cumplir los objetivos del Plan Decenal. Aunado a ello, se incorporan políticas nuevas como la creación de un nuevo currículo nacional (Constitución del 2008), e igualmente, se concibe la educación como un deber del Estado y con gratuidad hasta el tercer nivel de educación superior.

En el año 2009, el entonces Consejo de Educación Superior (CONESUP) y el Consejo Nacional de Evaluación y Acreditación (CONEA) realizan el proceso de evaluación y recategorización de las instituciones de educación superior, acciones que en el 2012, en el gobierno de Rafael Correa, provocaron el cierre de 14 universidades por parte de la Secretaría Nacional de Educación Superior, Ciencia, Tecnología e Innovación (SENESCYT) y por el Consejo de Evaluación, Acreditación y Aseguramiento de la Calidad de la Educación

\footnotetext{
3 La Constitución de Ecuador de 1998 fue la decimonovena Carta Magna (desde 1830) que se adoptó en el Ecuador en el gobierno interino de Fabián Alarcón, después del golpe de Estado en contra de Abdalá Bucaram.
} 
Superior (CEAACES) ${ }^{4}$, acciones respaldadas en la creación de nuevas leyes que justificaban la meta gubernamental de alcanzar y garantizar la calidad en la educación superior. Actualmente, Consejo de Educación Superior (CES), Senescyt y Ceaaces siguen siendo los principales organismos de control de la educación superior ecuatoriana.

En el año 2010 se propone la Actualización y Fortalecimiento Curricular de la Educación General Básica, sustentada en la pedagogía crítica y con el ideal de desarrollar en el estudiante destrezas con criterio de desempeño. En el año lectivo 2011-2012, en el Ecuador da inicio la aplicación del nuevo modelo de bachillerato denominado: Bachillerato General Unificado $(\mathrm{BGU})^{5}$, un bachillerato promulgado en la Ley Orgánica de Educación Intercultural (LOEI) que se obtiene después de haber aprobado los diez años de educación básica. Luego de aprobar los tres años de bachillerato, y mediante una serie de pruebas de acceso, el estudiante puede postular su ingreso a una diversidad de carreras profesionales en instituciones de educación superior (universidades e institutos superiores).

En el documento Ecuador. Indicadores Educativos 2011-2012 publicado por el Ministerio de Educación, se encuentran datos interesantes que obedecen a resultados estadísticos correspondientes a los períodos 2011-2012 y 2012-2013 en cuanto a las instituciones educativas, a docentes y a estudiantes, pero, sobre todo, presenta una visión panorámica de la estratificación del sistema educativo. De acuerdo con lo establecido en la Ley Orgánica de Educación Intercultural (LOEI) y en el Reglamento de la misma ley, los niveles educativos se clasificaban en: Educación Inicial, Educación General Básica (EGB) y Bachillerato.

\footnotetext{
${ }^{4}$ La Ley Orgánica Reformatoria a la Ley Orgánica de Educación Superior (LOES) establece que el nombre del Consejo de Evaluación, Acreditación y Aseguramiento de la Calidad-CEAACES- cambiará por el Consejo de Aseguramiento de la Calidad de la Educación Superior -CACES-, este tendrá a su cargo la regulación, planificación y coordinación del sistema de aseguramiento de la calidad de la educación superior y tendrá facultad regulatoria y de gestión. Entró en vigor el 2 de agosto de 2018 al publicarse en el Registro Oficial Suplemento N. 297 (Asamblea Nacional, 2018).

${ }^{5}$ Bachillerato General Unificado es un programa de estudios creado para ofrecer un mejor servicio educativo para todas las personas que hayan aprobado la Educación General Básica (EGB). Consta tres años y tiene como objetivos preparar a los estudiantes para la vida y la participación en una sociedad democrática, para el mundo laboral o del emprendimiento, y para continuar con sus estudios universitarios. Además del tronco común, los estudiantes pueden escoger entre dos opciones en función de sus intereses: el Bachillerato en Ciencias o el Bachillerato Técnico. La finalidad última de este tipo de bachillerato era evitar la dispersión de la oferta curricular y promover el acceso a las mismas oportunidades, con este tipo de bachillerato, las personas tendrían una base común de conocimiento que garantizaría la igualdad de oportunidades educativas. El bachillerato anterior exigía que los estudiantes eligieran una especialidad a los 14015 años de edad. El BGU está organizado por áreas de conocimiento de modo similar que la EGB.
} 
Siguiendo con la estratificación del sistema educativo, los niveles educativos descritos anteriormente, conforme al art. 27 del Reglamento General a la LOEI (2012), presentan los siguientes subniveles:

\section{Educación Inicial:}

1. Inicial 1, que no es escolarizado y comprende a infantes de hasta tres (3) años de edad; e,

2. Inicial 2, que comprende a infantes de tres (3) a cinco (5) años de edad.

\section{Educación General Básica:}

1. Preparatoria, que corresponde a $1^{\circ}$ grado de EGB y se ofrece a los estudiantes de cinco (5) años de edad;

2. Básica Elemental, que corresponde a $2^{\circ}, 3^{\circ}$ y $4^{\circ}$ grados de EGB y se ofrece a los estudiantes de 6 a 8 años de edad;

3. Básica Media, que corresponde a $5^{\circ}, 6^{\circ}$ y $7^{\circ}$ grados de EGB y se ofrece a los estudiantes de 9 a 11 años de edad; $y$,

4. Básica Superior, que corresponde a $8^{\circ}, 9^{\circ}$ y $10^{\circ}$ grados de EGB y se ofrece a los estudiantes de 12 a 14 años de edad.

\section{Bachillerato:}

1. El nivel de Bachillerato tiene tres (3) cursos y se ofrece a los estudiantes de 15 a 17 años de edad.

[...] el rango de edad sugerida de ingreso para el nivel de Educación Inicial corresponde de 3 a 5 años (LOEI, 2011: art. 40), 5 a 14 años para la EGB (LOEI, 2011: art. 42); y de 15 a 17 años para el Bachillerato (LOEI, 2011: art.). Los niños, niñas, adolescentes y jóvenes que exceden estas edades pueden ingresar al sistema educativo sin discriminación" (Ministerio de Educación, 2013, pp. 9-10).

Además, la oferta educativa del sistema nacional de educación, de acuerdo con el art. 38 de la LOEI (2011), se clasifica en escolarizada 6 y no escolarizada ${ }^{7}$. En el 2016 se hacen reformas en el currículo, el Ministerio de Educación propone el reajuste curricular a la propuesta del 2010, y a escasos tres meses de concluir el año 2018, ya se encuentra elaborado el primer borrador de una nueva reforma para el bachillerato ecuatoriano, una reforma que consiste en la eliminación del Bachillerato General Unificado para regresar al Bachillerato por especialidades.

\footnotetext{
${ }^{6}$ La educación escolarizada es acumulativa, progresiva y conlleva la obtención de un título o certificado. Esta puede ser catalogada en ordinaria o extraordinaria de acuerdo con el art. 23 del Reglamento General a la LOEI (2011, citado por Ministerio de Educación, 2013, p. 10). La oferta ordinaria corresponde a las personas en las edades establecidas y la oferta extraordinaria corresponde a las personas que superen dicho rango de edades 0 con estudios inconclusos.

7 La educación no escolarizada provee espacios educativos a lo largo de la vida y su currículo se adapta a las necesidades o particularidades del sector de la población que atiende caracterizándose como una oferta educativa esporádica y con una duración menor a un año escolar. Este tipo de educación implica cursos temporales que no conducen a la obtención de un título o certificado como la escolarizada (Ministerio de Educación, 2013, p. 10).
} 


\subsection{Aportes a la educación ecuatoriana de los últimos años}

En El currículo basado en competencias profesionales integradas en la universidad ecuatoriana (2017), se establece que las nuevas exigencias de la sociedad actual, a partir del año 2015, obligaron al Consejo de Educación Superior del Ecuador, a proponer "un conjunto de reformas que direccionen a las instituciones de Educación Superior del país hacia la revisión de sus currículos que por regla general estaban centrados en enfoques y paradigmas tradicionales, centrados en contenidos y en objetivos" (Aguilar-Gordón, 2017a , p. 132) para orientarlos hacia nuevos enfoques que garanticen la equidad, la inclusión y la calidad de la educación superior.

Lógicamente para hacer realidad estas reformas era necesario determinar los problemas de la realidad (actores y sectores vinculados) que integran el objeto de estudio de la profesión; identificar las tendencias de desarrollo local y regional de la sociedad actual; determinar las necesidades de formación, entre otros aspectos fundamentales para la propuesta (Aguilar-Gordón F. , 2017 b).

Las políticas cambiaron al Estado y con ello la educación experimentó algunas modificaciones, entre las que se enlistan: generación de nuevos proyectos y programas educativos; reformas a la designación de todas las personas que conforman el aparato administrativo en educación en todos sus niveles; nombramientos con base en concursos libres de méritos y oposición; nuevos procesos de evaluación y capacitación a docentes e instituciones de todos los niveles; equiparación entre lo que propone el currículo y el perfil profesional; creación de nuevas normas jurídicas como la Ley de Orgánica de Educación Intercultural (LOEI) y la Ley Orgánica de Educación Superior (LOES), se modificó la estructura administrativa de nivel central de estudios superiores, la creación de la SENESCYT; generación de becas de estudios y becas de investigación; mejora en los procesos investigativos; potenciación de estudios de cuarto nivel para las personas docentes universitarias; formación continua y revalorización del rol docente que incluye mejora de salario; nuevo modelo de gestión; actualización curricular; estándares de aprendizaje y de desempeño; apreciación de la diversidad cultural; nuevos criterios de calidad; creación de instituciones educativas con alta tecnología. Todos estos son aspectos significativos para el crecimiento del país, pero llevan consigo todo un conjunto de problemas que aún se encuentran sin resolver. 


\subsection{Nodos críticos de la educación ecuatoriana en los últimos años}

Se mencionan algunos nodos críticos que exigen ser repensados con miras a buscar alternativas de solución:

- Debilitamiento en el sentido de identidad nacional e incomprensión de la naturaleza plurinacional e intercultural del país (Aguilar-Gordón, 2017ª̣).

- Generación de un currículo rígido para la Educación Inicial, la Educación General Básica (EGB) y el Bachillerato General Unificado (BGU) que los docentes deben cumplir con para lograr el desarrollo de destrezas establecidas.

- El Bachillerato General Unificado ha perdido el horizonte para el cual fue creado, el perfil de salida de los estudiantes no es el ideal para su posterior vinculación en los procesos de educación superior. Luego de algunos años de puesta en práctica, se ha evidenciado que el estudiantado proveniente o egresado de BGU, con formación general y con aprendizajes básicos adquiridos como consecuencia de las asignaturas centrales o de tronco común, no han logrado desarrollar las competencias necesarias para involucrarse con facilidad en las instituciones de educación superior. Esto se encuentra demostrado por el número elevado de repeticiones y de deserción estudiantil de la población universitaria de los primeros niveles en las diversas carreras y en las distintas instituciones de educación superior.

- Examen de ingreso de los estudiantes que terminan el Bachillerato General Unificado (BGU) y que aspiran a iniciar una carrera universitaria. Un alto porcentaje de estudiantes que no aprueban el mencionado examen, que no obtienen el puntaje exigido para la carrera de su elección y para la institución de educación superior, pasan a engrosar las filas de la desocupación, incurren en actividades ilícitas con lo que se agudizan las problemáticas sociales. En el mejor de los casos, luego de varias postulaciones, logran un cupo para el ingreso en una institución de educación superior.

- Las personas estudiantes que aprueban el examen de ingreso a las universidades son orientadas hacia universidades de otras provincias, lo cual 
crea un problema económico de movilización para las aspiraciones educativas del estudiantado y sus familias.

- Divorcio entre educación media y estudios universitarios.

- La exigencia del uso de las TIC sin la adecuación de las instituciones públicas crea una desigualdad entre instituciones y sobre todo entre estudiantes con el mismo currículo.

- En todos los niveles educativos proliferan las mallas curriculares descontextualizadas.

- El Instituto Nacional de Evaluación Educativa (INEVAL) ${ }^{8}$ ejecuta pruebas estandarizadas de evaluación que no analizan el proceso, y solamente se concentran en los resultados del aprendizaje. No se pueden apreciar los errores del proceso, lo que se considera el mayor error, es que no se cambia el sistema de aprendizaje, los estudiantes no aprenden teorías que los lleve a comprender la realidad y a generar conocimientos. Se cambian programas, docentes, se mejora en infraestructura, pero no se revoluciona el proceso de aprendizaje.

- La exigencia del doctorado para catedráticos universitarios, cuando en el país no hay instituciones que ofrecen este tipo de estudios.

- Exigencia de programas de doctorado con altos componentes de presencialidad, sin considerar que los profesionales deben mantener sus trabajos (en los últimos meses esta situación se ha modificado).

- Validación de titulaciones de estudios de postgrado de acuerdo con listados con nombres de universidades extranjeras elegidas "por su prestigio internacional" pero que en realidad algunas de ellas no tienen el rigor científico y académico necesario para la oferta de este tipo de estudios. Se ha constatado que hay instituciones de educación superior del extranjero que se encuentran en los listados de "las mejores opciones para otorgar titulaciones

\footnotetext{
${ }^{8}$ Institución pública de Ecuador creada el 26 de noviembre de 2012 para la evaluación interna y externa del Sistema Nacional de Educación.
} 
de postgrado"; no obstante, en la práctica algunas de estas instituciones ofrecen postgrados a nivel de maestrías y de doctorados sin tomar en cuenta los perfiles de ingreso, masifican los ingresos de personas por el rédito económico que esto genera, otorgan dos titulaciones con un mismo trabajo de tesis (entregan título de maestría con la elaboración del primer capítulo de la tesis de doctorado y entregan el título de doctor con la complementación del trabajo iniciado en el programa de maestría). Es inaudito pero real. Es un atentado contra la inteligencia humana y un atentado contra quienes luego de dos o tres años de intensos estudios y de largos procesos investigativos han obtenido un título de maestría.

- Criterios uniformes de evaluación a las instituciones de educación superior sin considerar tiempo de creación ni modalidad de estudios.

- La llamada "autonomía responsable" es, en palabras de Enrique Ayala Mora (2015), "mutilada o incompleta" (p. 14). Siguiendo a Ayala-Mora (2015) se pierde la autonomía universitaria por cuanto los organismos de control universitario se encuentran integrados por delegados del gobierno y no por representantes de las instituciones, aspecto que hacía perder toda legitimidad. De modo que las nacientes políticas generaron una serie de atropellos y violaciones a los principios universitarios que paulatinamente eliminaron la autonomía que se pregonaba. Disfrazada de" revolución", se atropelló la tradición democrática universitaria y se eliminaron las organizaciones de la sociedad como sujetos de representación ante el estado (Ayala-Mora, 2015), todo fue camuflado bajo la creación de los Consejos de igualdad y de participación ciudadana.

- Siguiendo las reflexiones de Ayala-Mora (2015), encontramos que "en nombre de la reforma se ha instaurado un "colonialismo académico que niega la experiencia, la trayectoria de la universidad ecuatoriana e ignora su papel fundamental como repositorio de la cultura nacional..." (Ayala-Mora, 2015, p. 16) que paulatinamente la ido haciendo perder su sentido y horizonte, pues se 
impulsa la imitación a modelos universitarios del capitalismo, la burocratización de la investigación y la fragmentación del sistema universitario.

- El modelo de universidad que se quiso imponer conforme lo estipula AyalaMora (2015) no es adecuado para nuestro país porque se lo implanta con una clara ruptura de la relación universidad-sociedad y con la vigencia de una vinculación con la comunidad de corte asistencialista de cara al mercado y no a las necesidades de la sociedad. Es importante el diálogo con todos los sectores sociales que configuran y dan sentido a la existencia de la sociedad y del Estado.

- Universidad con corte cientificista que acalla la voz de su gente, que olvida las humanidades y abandona el espíritu crítico, reflexivo de los sujetos que dinamizan la historia de la sociedad. Impulso de las carreras técnicas.

- Baja calidad de los aprendizajes en todos los niveles educativos, especialmente a nivel de bachillerato donde el problema es más evidente.

- Reforma inconclusa y vigencia de esquemas pedagógicos tradicionales y de maltratantes y racistas relaciones de enseñanza aprendizaje.

- Docentes mal formados, mal capacitados y desmotivados por la continua persecución, por la sobrecarga laboral y por la baja remuneración.

- Ausencia de políticas integrales de capacitación, de estímulos y de un serio sistema de evaluación del desempeño que permita el crecimiento personal y social del profesorado.

- Movilidad de maestros del campo a la ciudad y abolición de instituciones educativas de educación primaria ${ }^{9}$ (o de los primeros años de educación básica) en las zonas rurales o zonas marginales con poca población estudiantil. Desde el año 2012, el Ministerio de Educación emprendió "el

${ }^{9}$ Anteriormente, la estructura educativa ecuatoriana estaba determinada por Jardín o Educación Infantil (de carácter opcional), Educación Primaria (de $1^{\circ}$ a $6^{\circ}$ grado), Educación Secundaria, dividida en ciclo básico $\left(1^{\circ}\right.$ a $3^{\circ}$ curso) y Ciclo Diversificado $\left(4^{\circ}, 5^{\circ}\right.$ y $6^{\circ}$ curso) con especializaciones. Más adelante, se dividió en Educación Inicial; Educación General Básica $\left(1^{\circ}\right.$ a $10^{\circ}$ año) y Bachillerato $\left(1^{\circ}, 2^{\circ}\right.$ y $\left.3^{\circ}\right)$. 
proceso de "reordenamiento de la oferta educativa" lo que generó la disminución de instituciones educativas. Este proceso de planificación pretende reestructurar las unidades o instituciones que se encuentran en funcionamiento..." (Antamba, 2015, p. 7). La disminución numérica de instituciones de escolaridad regular ordinaria de todos los sostenimientos fiscal, fiscomisional, municipal y particular, de acuerdo con Antamba (2015), se expresa en los siguientes términos: En el período 2009-2010, se contabilizan 18.578 instituciones fiscales; 702 fiscomisionales; 389 municipales; 6.150 particulares, con un total de 25.819 instituciones. Esta cifra se ve notablemente disminuida al finalizar el período 2013-2014, en el que se registran 17.311 instituciones fiscales; 569 fiscomisionales; 248 municipales; 4.559 particulares y un total de 22.687 instituciones educativas.

- Pagos excesivos por la construcción de las llamadas Unidades Educativas del Milenio (UEM) creadas en lugares estratégicos y con capacidad necesaria para abarcar las instituciones aledañas. Actualmente, algunas de estas instituciones se encuentran abandonadas y en proceso de destrucción.

- Sistema educativo atomizado, desarticulado y fragmentado en diversas ofertas educativas que exige una nueva propuesta integradora de rediseño curricular con metodologías innovadoras.

- Contratación de profesionales extranjeros que absorben una buena parte del presupuesto y que aprovechan las condiciones del país para usufructuar de manera egoísta.

\subsection{Desafíos}

Los nodos críticos antes señalados se convierten en los principales desafíos que tiene que enfrentar la educación ecuatoriana. Además, se plantean los siguientes:

Potenciar de forma integral e interdisciplinaria las prácticas profesionales de conocimientos y saberes contingentes, dinámicos y complejos mediante la preparación y contratación de profesionales proactivos e innovadores. 
Promover la profesionalización y capacitación continua de los docentes que respondan a las nuevas exigencias de la sociedad, que sean docentes: "[...] con capacidad de análisis crítico-reflexivo y propositivo sobre la situación nacional e internacional; sujetos críticospropositivos capaces de responder a las demandas surgidas de la sociedad del conocimiento y de las comunidades científicas" (Aguilar-Gordón, 2017aㅗ p. 135).

Propiciar el uso de metodologías, técnicas y estrategias que permitan comprender la diversidad de características del sujeto que aprende y la resignificación del proceso de enseñanza y de aprendizaje (Aguilar-Gordón, 2017ª̣).

Buscar mecanismos para "[...] propender hacia una educación de calidad que permita desarrollar habilidades cognitivas con la finalidad de potenciar en los estudiantes la capacidad investigativa, analítica, crítica, reflexiva y propositiva, de cuestionamiento, de formulación de hipótesis y de resolución de problemas" (Aguilar-Gordón, 2017b, p. 46).

Cumplir con su tarea fundamental: contribuir para el perfeccionamiento de las personas, pues:

la educación consiste en lograr que una persona haga por sí misma lo que debe hacer, que desarrolle habilidades y destrezas que le permitan representar y comprender el mundo; interpretar la existencia y emprender en la vida misma, para ello es preciso reconocer la historicidad del proceso educativo, la historicidad de la pedagogía como reflexión sobre el proceso de formación (Aguilar-Gordón, 2008, p. 44)

Coordinar los diferentes procesos de enseñanza-aprendizaje con miras a alcanzar una educación tendiente a la consolidación del carácter y a la formación de la moralidad de las personas como uno de los fines primordiales de la educación (Aguilar-Gordón F. , 2008).

Reconocer en los nuevos rediseños curriculares de todos los niveles educativos la presencia de los saberes filosófico y pedagógico como campos interdisciplinares rigurosos, con historicidad propia y como saberes que propician respuestas a la problematicidad humana de los últimos tiempos, aspecto que permite comprender lo que Bedoya (2003) denomina "el currículo integrado sustentado en el concepto de formación como su eje directriz,..."(p. 152). Lo anterior evidencia la necesidad de realizar una transformación curricular que contenga al menos dos referentes fundamentales: reflexión epistemológica (toma de conciencia y actitud crítica) e integración real de saberes a través de la aplicacación de didácticas generales y especiales que generen nuevas formas de enseñar y nuevas 
formas de aprender, mediadas por sistemas dialógicos y construccionistas. La calidad ha sido considerada por el Ministerio de Educación como un eje estratégico:

...que busca mejorar los servicios que ofrece, los actores que lo impulsan y los resultados que se generan, para cumplir con las metas establecidas en el Plan Nacional del Buen Vivir y en el Plan Decenal de Educación, como pasos fundamentales para el pleno desarrollo del país (Antamba, 2015, p. 19).

Esto debe reflejarse en la mejora del sistema educativo ecuatoriano en todas las áreas sometidas a evaluación con la finalidad de superar los resultados arrojados por el "Segundo Estudio Explicativo y Comparativo (SERCE), realizado en 2006, donde Ecuador estuvo entre los tres países de la región con peor desempeño educativo (7.8)" (Antamba, 2015, p. 19). Es importante considerar que la calidad de la educación a nivel de estudios superiores ha sido una constante del debate nacional, en su momento el CONEA (2003) sostenía que la calidad de la educación superior se encuentra ligada al conjunto de factores que inciden en la formación profesional, el modo de producción del conocimiento, la construcción de valores morales y éticos y su difusión social a partir del logro de los fines, objetivos y metas consignados en la visión, misión y el plan institucional" (CONEA, 2003, p. 7). En aquel entonces las personas creían que la calidad de la educación superior lleva consigo la aptitud, el eficiente manejo de los recursos y los esfuerzos, y acciones necesarias para concretar los propósitos de la institución (CONEA, 2003).

No obstante, la calidad del trabajo universitario inplica capacidad concreta para incidir en los cambios que requiere la sociedad para hacerla más productiva, equitativa, justa y solidaria. La calidad en la formación de profesionales; en la investigación; en las actividades de vinculación con la colectividad; en la administración y en la gestión universitaria han sido una preocupación constante en la educación superior ecuatoriana, de ahí que, un desafío importante sea propiciar principios elementales tendientes a la búsqueda de una verdadera excelencia académica; respeto y fortalecimiento de la institucionalidad jurídica; transparencia admnistrativa y financiera; conciencia de nuestra identidad pluricultrual y multiétnica; compromiso con el cambio social, los derechos humanos, la solidaridad, la justicia social y la democracia participativa. Para realizar procesos adecuados es importante establecer indicadores y estándares adecuados de calidad. En tal sentido, el mismo CEAACES, al referirse a las instituciones de educación superior, señala: 
La IES promueve el comportamiento ético de la comunidad universitaria en todos los ámbitos académicos de acuerdo a sus códigos o políticas institucionales, y posee instancias ampliamente conocidas por todos los miembros de la comunidad universitaria que resuelven los problemas 0 situaciones relacionados a su incumplimiento (CEAACES, 2018, p. 12)

El organismo de educación superior sostiene que como política de acción afirmativa, la institución de educación superior (IES) debe aplicar "políticas y normativas efectivas que garanticen la igualdad de oportunidades en el acceso, permanencia, movilidad y egreso del sistema, fomenta la equidad de género, credo, orientación sexual, etnia, preferencia política, condición socio.económica o discapacidad” (CEAACES, 2018, p. 9). En todo caso, la construcción del modelo de evaluación institucional de las universidades y escuelas politécnicas también ha sufrido un proceso evolutivo en el 2013, en la propuesta 2015-2016 para rediseños y para la recategorización y el modelo actual para el 2018.

\section{Conclusiones}

El fundamento de la educación se encuentra en determinar la esencia y el fin del ser humano como su principal protagonista. Los hitos fundamentales de la educación a través del tiempo invitan a repensar en el sujeto que aprende y en el contexto que le rodea. El sistema educativo ecuatoriano ha progresado en los últimos tiempos, pero tiene algunos obstáculos y nodos críticos que resolver, por lo que se puede afirmar que, en el sistema educativo ecuatoriano, "todavía no ha muerto el viejo estado ni ha nacido el nuevo", se experimenta al mismo tiempo un doble y mismo proceso que conlleva evolución-involución.

La transformación educativa exige realizar una ruptura crítica y epistemológica con los modelos tradicionales. La transformación es necesaria, exige esfuerzos y decisiones políticas de carácter colectivo en la que participen diversos actores de la sociedad y representantes de la economía, de la política, de las organizaciones sociales, de medios de comunicación y de toda la población en general. El destino del país depende del destino de la educación. Es necesario volver al sujeto con la finalidad de vivenciar lo que establece el artículo 27 de nuestra Constitución del año 2008, el cual sostiene que:

la educación se centrará en el ser humano y garantizará su desarrollo holístico, en el marco del respecto a los derechos humanos, al medio ambiente sustentable y a la democracia; será participativa, obligatoria, intercultural, democrática, incluyente y 
diversa, de calidad y calidez; impulsará la equidad de género, la justicia, la solidaridad y la paz; estimulará el sentido crítico, el arte y la cultura física, la iniciativa individual y comunitaria, y el desarrollo de competencias y capacidades para crear y trabajar (Asamblea Nacional del Ecuador, 2008, p. 16)

Es preciso hacer de la educación una tarea transformadora, analítica, crítica, reflexiva y propositiva. Se deberá propiciar un sistema educativo dialógico que permita la construcción y la transformación del sujeto que aprende, que piensa, que siente y que actúa; un sistema educativo donde nuestros gobernantes tengan presente y encuentren las estrategias adecuadas para hacer realidad el art.26 de la Constitución (2008) que establece:

[...] La educación es un derecho de las personas a lo largo de su vida y un deber ineludible e inexcusable del Estado. Constituye un área prioritaria de la política pública y de la inversión estatal, garantía de la igualdad e inclusión social y condición indispensable para el buen vivir. Las personas, las familias y la sociedad tienen el derecho y la responsabilidad de participar en el proceso educativo. (Asamblea Nacional del Ecuador, 2008, p. 16)

\section{Referencias}

Aguilar-Gordón, Floralba. (2008). Estructura, relaciones, límites y perspectivas de la ética y educación. Sophia: Colección de Filosofía de la Educación, (5), 39-78. DOI https://doi.org/10.17163/soph.n5.2008.02

Aguilar-Gordón, Floralba. (2017a). El currículo basado en competencias profesionales integradas en la universidad ecuatoriana. REXE. Revista de estudios y experiencias en educación, 16(31), 129-154.

Aguilar-Gordón, Floralba. (2017b). Estrategias didacticas para el desarrollo de operaciones mentales en el sujeto que aprende. Tópos. Para un debate de lo educativo, (9), 45-54.

Aguilar-Gordón, Floralba. (2017c). Fundamentos, sentido y significado del conocimiento. En Aguilar-Gordón, Floralba y otros (2017). Fundamentos epistemológicos para orientar el desarrollo del conocimiento (págs. 49-101). Quito, Ecuador: Abya-Yala.

Agustín (2018). Agustín de Hipona: Profesor, Maestro, Pedagogo. EcWiki. Recuperado de http://ec.aciprensa.com/wiki/Agust\%C3\%ADn_de_Hipona:_Profesor,_Maestro,_Pedago go

Alonso, José. (2015). Historia general de la educación. México: Col. Viveros de Asis. 
Antamba, Luis. (2015). Estadística Educativa. Reporte de Indicadores (Vol. 1). QuitoEcuador: Ministerio de Educación.

Asamblea Nacional del Ecuador. (2008). Constitución de la República del Ecuador. Montecristi, Ecuador: La Asamblea.

Ayala-Mora, Enrique. (2015). La maldición de la universidad silenciosa.La educación superior en el debate de los temas nacionales. Anales,58, 9-18.

Bedoya, Iván. (2003). Epistemología y Pedagogía. Ensayo histórico crítico sobre el objeto y método pedagógicos. Bogotá, Colombia: Ecoediciones.

Consejo de Evaluación, Acreditación y Aseguramiento de la Calidad de la Educación Superior. (2018). Modelo de evaluación institucional de Universdades y Escuelas Politécnicas 2018. Quito, Ecuador: Autor.

Consejo Nacional de Evaluación y Acreditación. (2003). La calidad en la universidad http://unesdoc.unesco.org/images/0014/001496/149614s.pdf

García, María. (2017). Aprendiendo a ser humanos: una Antropología de la educación. Navarra: EUNSA.

Kant, Inmanuel. (1803). Pedagogía. Alemania: Universidad ARCIS.

Knobel, Mauricio. (1964). El desarrollo y la maduración en psicología evolutiva. Revista de Psicología, 1, 1-5.

Ley Orgánica de Educación Intercultural. (2011), Registro Oficial N 417 (II supl). Quito, Ecuador: Ministerio de Educación.

Marrow, Henry Irenee. (2014). Historia de la Educación en la antigüedad. España: AKAL.

Ministerio de Educación del Ecuador (2013). Ecuador: Indicadores educativos 2011-2012. Ecuador: Ministerio de Educación.

Moreira, Andrés. (2013). Historia del sistema educativo del Ecuador. Monografías, 1-24.

Redondo, Emilio; Cárceles, Concepción; Gutiérrez, Aurora; Laspalas, Javier; Pernil, Paloma y Vergara, Javier. (2014). Introducción a la historia de la educación. Barcelona, España: Ariel Educación.

Ley Orgánica de Educación Intercultural (26 de julio, 2012). Suplemento al Registro Oficial, (pp. 1-25). Ecuador: Ministerio de Educación. 
Organización de las Naciones Unidas para la Educación, la Ciencia y la Cultura. (2008). Un enfoque de la educación para todos basado en los derechos humanos. New York: División de Comunicaciones, UNICEF.

Uzcátegui, Ramón y Junguittu, Rosa. (2017). Historia, historia de la educación y su enseñanza. Venezuela: Saber UCV. 